\title{
Dêixis pessoal e verbos na construção de um objeto de discurso argumentativamente orientado
}

\author{
Ana Lucia Tinoco Cabral ${ }^{1}$ \\ Leonor Werneck dos Santos ${ }^{2}$
}

\begin{abstract}
This article deals with the argumentative strategies used in the writing of Getúlio Varga's testament letter, building an image of the suicidal leader before his people; marked by the relatively contrast to his opponents. The study aims at presenting the objects of discourse writing process used in the letter, particularly, the ones used by Getúlio, who constitutes the "I" in an intersubjective relationship with the "people", to whom he addresses the "I"; thus setting conflicts with his opponents, from whom he distances himself. The research is grounded in renowned Text Linguistics authors' studies, particularly the ones by Apothéloz and Pekarek Doehler (2003), Conte (2003), Mondada (2005) Francis (1996), Mondada and Dubois (2003), Cavalcante (2003, 2011), Koch (2003, 2015), Koch and Elias (2006, 2009), Marcuschi (2005); among others. The analyses relate the target processes to the text argumentative shaping, with particular emphasis on the indirect anaphora, the personal deixis and the use of verbs as a strategy employed in the writing process of an argumentative-oriented object of discourse.
\end{abstract}

Keywords: reference; argument; dêixis; verbs; objects of discourse.

Resumo: Este artigo trata de estratégias argumentativas presentes na construção da carta testamento de Getúlio Vargas, a fim de construir uma imagem do governante suicida perante o povo, marcando o contraste relativamente a seus opositores. O objetivo é apresentar um estudo do processo de construção dos objetos de discurso presentes na carta, especialmente, o próprio Getúlio, que constitui "eu", numa relação intersubjetiva com "o povo", a quem se dirige "eu", e marcando o confronto com seus opositores, de quem se distancia. $\mathrm{O}$ trabalho fundamenta-se em autores consagrados da Linguística de Texto - especificamente Apothéloz e PekarekDoehler (2003), Conte (2003), Mondada (2005) Francis (1996), Mondada e Dubois (2003), Cavalcante (2003, 2011), Koch $(2003,2015)$, Koch e Elias (2006, 2009), Marcuschi (2005), dentre outros. As análises relacionam processos referenciais à arquitetura argumentativa do texto, observando especialmente anáforas indiretas, dêixis de pessoa e o emprego dos verbos como estratégia utilizada no processo de construção do objeto de discurso argumentativamente orientado.

Palavras-chave: referenciação; argumentação; dêixis; verbos; objetos de discurso. 
A Carta Testamento de Getúlio Vargas constitui o discurso de despedida supostamente escrito pelo então presidente, algumas horas antes de seu suicídio, em 24 de agosto de 1954. Nela, Getúlio procura expor ao povo brasileiro as razões de seu fracasso que culminou com o suicídio. Propomos, neste capítulo, uma análise da carta, observando algumas estratégias argumentativas presentes na construção do texto - como uso de processos referenciais e de verbos - com o fim de construir uma imagem do governante suicida perante o povo, marcando o contraste relativamente a seus opositores.

Tendo em vista que, no processo de produção do texto, se constroem objetos de discurso marcados por essa intenção argumentativa, que se concretiza por meio de escolhas linguísticas subjetivas, apoiamo-nos em Kerbrat-Orecchioni (1997 [1980]), autora dedicada à exploração dos procedimentos por meio dos quais o locutor imprime sua marca no enunciado, seja explicitamente, seja implicitamente. A pesquisadora defende que as unidades lexicais são em si mesmas, em língua, carregadas de uma dose mais ou menos forte de subjetividade, uma vez que, para essa estudiosa, as palavras da língua são apenas símbolos substitutivos e interpretadores das coisas. De acordo com a estudiosa, são os operadores de subjetividade particularmente visíveis e eficazes que permitem ao locutor de se situar em relação aos conteúdos daquilo que ele diz. Essa observação põe em evidência que a língua nos oferece os meios para marcar subjetivamente os enunciados, indicando a direção argumentativa desejada.

A partir dessas considerações, é nosso objetivo, no presente texto, apresentar um estudo do processo de construção dos objetos de discurso presentes na carta, especialmente, o próprio Getúlio, que constitui “eu”, numa relação intersubjetiva com "o povo", a quem se dirige "eu", e marcando o confronto com seus opositores, de quem se distancia. Com base em autores consagrados da Linguística de Texto - especificamente Apothéloz e Pekarek Doehler (2003), Conte (2003), Mondada (2005) Francis (1996), Mondada e Dubois (2003), Cavalcante (2003, 2011), Koch (2003, 2015), Koch e Elias (2006, 2009), Marcuschi (2005), dentre outros - conceituaremos texto e referenciação. Ao longo da análise da carta testamento, relacionaremos os processos referenciais à arquitetura argumentativa do texto, observando especialmente anáforas indiretas e dêixis de pessoa, destacando a importância das inferências para a solidificação da intenção argumentativa e destacaremos o emprego dos verbos como estratégia utilizada no processo de construção do objeto de discurso argumentativamente orientado.

\section{Sobre o conceito sociointeracional de texto e de referenciação}

Desde o final da década de 1990, predomina na Linguística de Texto a perspectiva sociocognitiva e interacional, que defende que a compreensão de textos depende do acionamento de conhecimentos prévios, estando, portanto, ligada a aspectos sociocognitivos. Assim, segundo Cavalcante (2011, p. 9), o texto tem sido considerado

como fenômeno comunicativo, o que supõe uma visão de coerência/coesão e de textualidade que não depende exclusivamente de propriedades inerentes à organização dos elementos no cotexto, mas de um contexto sociocultural mais amplo, o que inclui uma série de atividades interpretativas dos co-enunciadores.

Além disso, precisamos considerar os textos como materializações de gêneros, o que faz com que estejam submetidos às regularidades linguísticas e temáticas desses gêneros, 
conforme a situação enunciativa na qual circulam. Afinal, consideramos que a atividade de leitura depende de estratégias e de graus de percepção de aspectos inferenciais e referenciais, para não somente articular conhecimentos prévios como também colaborar com o levantamento de hipóteses. Por esse motivo, Marcuschi (2008, p. 72) alerta para a importância de considerar o objetivo dos interlocutores e o contexto sociocognitivo:

O texto é o resultado de uma ação linguística cujas fronteiras são, em geral, definidas por seus vínculos com o mundo no qual ele surge e funciona. Esse fenômeno não é apenas uma extensão da frase, mas uma entidade teoricamente nova. (...) falamos de texto como um evento que atualiza sentidos e não como uma entidade que porta sentidos na independência de seus leitores.

Dessa forma, se consideramos que a construção de sentidos é um processo colaborativo, decorrente do acionamento de conhecimentos prévios, os processos referenciais também precisam ser considerados como algo em permanente construção, já que os objetos de discurso são construídos, interativa e discursivamente, e não preexistem ao discurso. Essa perspectiva tem sido defendida, atualmente, pela Linguística de Texto, uma vez que os objetos de discurso precisam ser considerados como em constante ativação e reativação, conforme se processa a leitura. Por isso, para Koch (2003, p. 30):

O sentido de um texto, qualquer que seja a situação comunicativa, não depende tão somente da estrutura textual em si mesma. Os objetos de discurso a que o texto faz referência são apresentados em grande parte de forma lacunar, permanecendo muita coisa implícita. $\mathrm{O}$ produtor do texto pressupõe da parte do leitor/ouvinte conhecimentos textuais, situacionais e enciclopédicos e, orientando-se pelo Princípio da Economia, não explicita as informações consideradas redundantes. Ou seja, visto que não existem textos totalmente explícitos, o produtor de um texto necessita proceder ao "balanceamento" do que necessita ser explicitado textualmente e do que pode permanecer implícito, por ser recuperável via inferenciação.

Esses conceitos alargados de texto e referenciação partem do pressuposto de que o texto deve ser concebido sob um caráter sociointeracional, o que exige considerar uma postura ativa do leitor, na busca por preencher as lacunas textuais, num cálculo mental de levantamento de hipóteses que depende do contexto sociocognitivo. Além disso, essa visão sociocognitiva e interacional da referenciação enfatiza a íntima relação entre coesão e coerência, que colaboram para o projeto de dizer e que precisam ser percebidas em conjunto (CAVALCANTE; SANTOS, 2012).

Assim, o processo de referenciação não é a simples substituição de um termo por outro equivalente, mas uma prática discursiva que pressupõe uma interação entre os sujeitos do discurso, responsáveis por escolhas significativas para representar os referentes de acordo com a sua proposta de sentido (CAVALCANTE; CUSTÓDIO Fo.; BRITO, 2013). Só é possível identificar os objetos de discurso retomados ou antecipados a partir de associações cognitivas, e os processos referenciais colaboram na construção dos efeitos de sentido das escolhas linguísticas no projeto de dizer. Por isso, é necessário fazer associações, conforme nossos conhecimentos prévios, para compreender as cadeias referenciais, e, conforme alertam Mondada \& Dubois (2003, p. 20), os objetos de discurso são analisados tendo em vista a coconstrução de sentido, por serem "objetos constitutivamente discursivos":

passando da referência à referenciação, vamos questionar os processos de discretização e de estabilização. Esta abordagem implica uma visão dinâmica que leva em conta não somente 
o sujeito "encarnado", mas ainda um sujeito sociocognitivo mediante uma relação indireta entre os discursos e o mundo. Este sujeito constrói o mundo ao curso do cumprimento de suas atividades sociais e o torna estável graças às categorias - notadamente às categorias manifestadas no discurso.

Portanto, concordamos com Koch (2015, p. 35), que destaca que:

O emprego de uma descrição nominal, com função de categorização ou recategorização de referentes, implica sempre uma multiplicidade de formas de caracterizar o referente(...). Trata-se, em geral, da ativação, dentre os conhecimentos culturalmente pressupostos como compartilhados, de características ou traços do referente que devem levar o interlocutor a construir dele determinada imagem(...) uma de suas funções textual-interativas específicas é a de imprimir aos enunciados em que se inserem, bem como ao texto como um todo, orientações argumentativas conformes à proposta enunciativa do seu interlocutor.

Os processos referenciais costumam ser classificados de maneiras diferentes, conforme os pressupostos teóricos que norteiam a análise. Embora não seja nosso objetivo neste artigo polemizar a respeito de nomenclaturas e definições, é importante destacarmos alguns aspectos relevantes que vêm suscitando debates (cf. SANTOS; CAVALCANTE, 2014). Partindo desta revisão teórica mais ampla e sociocognitiva, discutiremos as anáforas e a dêixis, porém analisaremos apenas os casos de anáfora indireta e dêixis pessoal, na carta testamento.

\section{A respeito da (inter)subjetividade}

A enunciação, de acordo com Benveniste (1997[1974], p.81) "supõe a conversão individual da língua em discurso"; trata-se do processo pelo qual o indivíduo põe em uso o sistema linguístico. Sendo assim, considerando que os instrumentos da enunciação são as marcas da conversão individual da língua em discurso, admitimos que o sujeito necessariamente deixa suas marcas no enunciado; essa presença constitui o parâmetro para as condições necessárias de enunciação e para a construção dos sentidos do texto. São as escolhas em função de um querer dizer $(\mathrm{KOCH}, 2005)$ que permitem a construção dos objetos de discurso.

Dessa forma, o sujeito toma a língua como instrumento para realizar seus propósitos, insere-se no enunciado e constrói com ele objetos de discurso que instauram seus pontos de vista a respeito da realidade instaurada no discurso. Ducrot (1984), ao tratar da relação entre enunciação e língua, ensina que esta tem como função primordial colocar à disposição dos interlocutores um conjunto de modos de ações estereotipadas que lhes permitam representar e se impor papéis, mutuamente. Esse postulado de Ducrot vem ao encontro dos ensinamentos de Benveniste (1997 [1966], p.259), para quem “é na linguagem e pela linguagem que o homem se constitui como sujeito". Assim, o sujeito que diz "eu" também constrói relativamente a "eu" uma representação, orientada argumentativamente em direção a um ponto de vista sobre "eu", em relação a "tu" e em relação a "ele". Podemos, então, afirmar que "eu" constitui um objeto de discurso, construído no desenvolvimento da textualidade.

Para Benveniste (1997[1966]), a linguagem é uma possibilidade da subjetividade, e o discurso provoca a emergência dessa subjetividade, cuja instalação cria a categoria da pessoa. $\mathrm{O}$ enunciador, na realidade, lança mão de muitos procedimentos para imprimir 
sua marca no enunciado, seja explicitamente, seja implicitamente, por meio de escolhas lexicais e sintáticas que atendem suas intenções. Por isso, Kerbrat-Orecchioni (1980, 1997) defende que as unidades lexicais são em si mesmas, em língua, carregadas de uma dose mais ou menos forte de subjetividade. Desse ponto de vista, o estudo do texto inclui diversas categorias de fenômenos linguísticos que marcam atitudes do enunciador perante o que ele enuncia (BENVENISTE, 1997[1974], p.85).

Ducrot $(1972,1984)$ lembra, porém, que o sujeito enunciador, muitas vezes, se "esconde" por detrás de falsa objetividade, utilizando-se dos pressupostos do enunciado, por exemplo, para mascarar a subjetividade. Entretanto, Kerbrat-Orecchioni $(1980,1997)$ alerta que toda unidade lexical é subjetiva: por meio delas, damos sentido ao mundo, criamos uma realidade discursiva e interagimos com ela. A esse respeito vale lembrar os ensinamentos de Mondada e Dubois (2003, p.20), para quem as práticas de produção e interpretação de texto constituem "uma construção de objetos cognitivos e discursivos na intersubjetividade das negociações, das modificações, das ratificações de concepções individuais e públicas do mundo".

Na carta testamento, é perceptível a marca de subjetividade, por meio do uso de verbos e de estratégias de referenciação. Quando, no processo de referenciação, o objeto de discurso se identifica com "eu", o processo toma uma relação com a questão da subjetividade e, necessariamente, com a intersubjetividade. A dêixis, por exemplo, nos remete à questão do sujeito enunciador e sua relação com os demais sujeitos inseridos no texto - eu, tu e ele -, o que nos conduz à problemática da enunciação e, por conseguinte, aos postulados de Benveniste.

\section{Dêixis de pessoa: da teoria à análise da carta testamento}

Na literatura linguística tradicional (cf. LYONS, 1977; BÜHLER, 1982; LEVINSON, 1983), a dêixis é considerada uma marca por meio da qual se explicita pessoa, tempo, espaço da situação enunciativa, partindo da origo, tomando como ponto de partida o eu ${ }^{3}$. A dêixis é tomada, portanto, de modo egocêntrico, a partir do eu que fala, do aqui e do agora do momento da enunciação, por vezes vindo acompanhada de gestos para "apontar para" algo ou alguém.

Há, porém, aspectos relacionados à dêixis que merecem destaque, como a distinção entre anáfora e dêixis. Segundo Reichler-Béguelin (1988, p. 20-21), a principal diferença entre esses dois processos referenciais se concentra em como a memória discursiva é alimentada, e não como a informação é recuperada:

referência dêitica e referência anafórica serão descritas como um lembrete das informações contidas no conhecimento compartilhado, nas representações mentais de parceiros da interlocução. A diferença está no nível do modo de validação dessas informações: na anáfora ou referência contextual, a informação é validada porque é um objeto de discurso no texto; na dêixis, ele é validado porque é o objeto de uma percepção concomitante à enunciação. A oposição dêixis /anáfora se relaciona à maneira como é alimentada a memória discursiva e não como as informações são recuperadas. ${ }^{4}$

3 Neste artigo, não trataremos dos outros subtipos de dêixis, como textual, de memória etc.

4 Tradução nossa: "référence déitique aussi bien que référence anaphorique seront décrites comme appel ou rappel d'informations contenues dans le stock de connaissances officiellement partagées, dans les représentations mentales communes aux partenaires de l'interlocution, la différence se situant au niveau du mode de validation de ces informations: dans l'anaphore ou la référence contextuelle, l'information est validée parce 
Assim, podemos postular um caráter híbrido entre esses processos, concordando com Cornish (2007, p. 1), que defende que ambos são procedimentos discursivos complementares que operam no nível de organização da memória, permitindo que os interlocutores gerenciem o processamento textual. Para Cornish (2005, p. 201), a diferença maior reside no fato de haver uma certa ruptura causada pela dêixis no texto:

"Deixis", por outro lado, é um procedimento que se baseia no contexto do enunciado para reorientar a atenção do interlocutor em direção a algo associado a este contexto (daí que é lhe é potencialmente familiar), mas para o qual se presume que o interlocutor já não esteja presente. Como Kleiber tem observado, a dêixis provoca uma ruptura na continuidade do discurso no ponto onde o procedimento dêitico é utilizado, de forma que o interlocutor seja convidado a "sair" deste contexto de discurso para compreender a nova referência em termos de situação atual do enunciado - ou, alternativamente, um aspecto de um mesmo referente, que já tenha sido enfocado anteriormente. [grifo do autor] ${ }^{5}$

Essa fluidez entre os conceitos de anáfora e dêixis decorre da percepção atual de que aspectos contextuais (geralmente associados à dêixis) também estão presentes e são acionados para a compreensão de anáforas, por isso, para Schiffrin (1990, p. 267), mesmo o texto é contextual. Também para Fonseca (1992, p.136):

A relação de dependência que liga o discurso ao seu contexto é uma relação reversível: se a linguagem é dependente do contexto, também se pode dizer que o contexto é dependente da linguagem na medida em que é por ela criado. Trata-se, pois, de uma relação de interdependência. Uma relação dinâmica e dinamizadora: o discurso e o contexto não são objectos estáveis, são processos entre os quais se estabelece uma interacção construtiva. [grifos da autora]

Geralmente, pesquisas sobre dêixis pessoal, espacial e temporal analisam aspectos mais linguísticos que textuais-discursivos, enfatizando, por exemplo, o uso de demonstrativos, tempos verbais, pronomes pessoais, advérbios. Porém, quando analisamos alguns textos, como discursos de políticos e a carta-testamento de Getúlio Vargas, podemos observar aspectos sobre a dêixis que denotam seu papel na arquitetura argumentativa. Isso ocorre, segundo Santos \& Cavalcante (2014, p. 243) porque, se

concebemos o texto como processo e enfatizamos a importância da referenciação na construção de sentido, precisamos analisar os exemplos observando esse processo sociocognitivo e interacional, complexo e abrangente. Dessa forma, os referentes só podem ser concebidos como novos ou velhos na perspectiva do cotexto, já que, do ponto de vista dos participantes da enunciação, o falante investe, em geral, no pressuposto de que a entidade

qu'elle est object de discours ailleurs dans le texte; dans la deixis, elle est validée parce qu'elle fait l'object d'une perception concomitante à l'énonciation. L'opposition deixis/anaphore porte donc sur la façon dont est alimentée la mémoire discursive, et non sur la façon don't les informations en sont extraites."

5 Tradução nossa: “'Deixis' on the other hand, is a procedure which relies on the utterance context to re-direct the interlocutor's attention towards something associated with this context (hence which is potentially familiar to him or her), but to which s/he is assumed not already to be attending. As Kleiber and other pragmasemanticists have observed, deixis causes a break in the continuity of the discourse at the point where the deictic procedure is used, so that the interlocutor is invited to "step out" of this discourse context to grasp a new referent in terms of the current situation of utterance - or alternatively an aspect of a same referent, which has already been focused upon." 
a ser referida será de algum modo acessível ao destinatário, ou pelas pistas contextuais, ou pelo saber comum a ambos, ou pelos indícios da situação comunicativa real.

Segundo Maalej (2013, p. 639) - que analisou o uso dos pronomes Eu/Nós/Vocês nos três últimos discursos de Osni Mubarak, antes de este ser deposto do cargo de presidente do Egito -, a dêixis de pessoa precisa ser considerada segundo suas dimensões discursivas e ideológicas: "Para além do seu uso discursivo, pronomes têm demonstrado uma importante dimensão ideológica". Citando Pennycook, Maalej concorda com a dimensão política do pronome, segundo o qual "pronomes são profundamente enraizados na nomeação de pessoas e grupos e são, portanto, sempre políticos no sentido de que eles sempre implicam relações de poder". Assim, mesmo o 'eu', além de indicar o enunciador, "pode operar como um meio de construção do Outro: pode estar em oposição a qualquer 'você' ou 'eles' da mesma forma que 'nós"”.'.

Na sua análise, Maalej (2013, p. 640) defende que enquanto EU ancora o discurso de maneira egocêntrica e autocentrada, NÓS pode ser inclusivo e solidário, ou exclusivo e indicador de rejeição, e essa duplicidade de papéis deste pronome, de certa forma, define também de que maneira VOCÊ(S) e ELE(S) aparecem no discurso: simplesmente como a outra parte, o outro, ou como alguém ou um grupo cuja diferença se quer realçar. E essa concepção do EU e do OUTRO, construída no discurso, marca uma postura ideológica, dependente da visão de mundo de um grupo politicamente dominante, por exemplo.

Por isso, Maalej concorda com Marmaridou (2000, p.98) quando a autora defende a inseparabilidade entre dêixis de pessoa e social, uma vez que esta "fornece ancoragem para linguagem em seu contexto interacional imediato de uso". Para Maalej (2013, p. 640), o "papel social dos participantes determina se, por exemplo, NÓS é inclusivo ou exclusivo, o que sugere fortemente que a dêixis de pessoa está intimamente ligada à dêixis social". Como exemplo, podemos citar os comentários de Maalej a respeito do uso de EU/ VOCÊ/NÓS no discurso de Mubarak: no início do primeiro discurso dirigido à Nação, aparece $\operatorname{VOCÊ}(\mathrm{S})$ (o povo), mas depois essa referência desaparece e só ressurge no último discurso; em todos os discursos, o EU refere-se não à pessoa, mas ao cargo, é um EU presidencial, muitas vezes com conotação messiânica, de salvador da Pátria, ou mesmo pai de todos; à medida que as pressões contra seu governo aumentam, Mubarak marca o discurso com a presença de ELES, representando aspectos negativos, são os baderneiros, os inimigos do país, contra as "boas pessoas" que ele representa; no último discurso, há um EU a cada treze palavras, sempre associado ao "Pai da nação", e o VOCÊ(S) aparece sempre associado ao filho/pai/irmão que precisa de proteção; o NÓS nunca inclui EU + o povo, antes refere-se a EU + os demais políticos, ou seja, é um NÓS excludente em relação ao povo, destinatário pressusposto.

Passando, agora, à análise dos casos de dêixis pessoal na carta-testamento, encontramos algumas semelhanças em relação ao que Maalej concluiu em sua pesquisa. Na carta, observamos o uso da dêixis pessoal especialmente marcada pela 1a pessoa do singular (EU) e 2a pessoa do plural (VÓS), associadas à 1a pessoa do plural (NÓS). Segundo Rodrigues et al. (2012, p. 290), as ocorrências de Vós/Vos/Vosso(a,s), na carta-testamento, "revelam uma interação direta do enunciador com o interlocutor ao qual se dirige: 'o povo brasileiro"'. O texto inteiro é marcado pela subjetividade e pela emoção, e o uso da 2a pessoa interpela o interlocutor. Por se tratar de uma carta e pelo fato de ser uma carta "testamento", a interpelação ao interlocutor - e um interlocutor que "herda" algo - seria óbvia. Porém, o jogo pessoal entre EU/VÓS/NÓS parece ir além da simples menção às pessoas do discurso, mesmo

6 Tradução nossa: “I' can also operate as one half of a construction of the Other: It can stand in opposition to any 'you' or 'they' in the same way that 'we' does." 


\section{Conexão Letras}

porque aparece também no texto a 3a pessoa do plural, de maneira bastante indefinida - em expressões como "as forças" e em verbos com sujeito indeterminado.

Tomando de empréstimo o plano do texto elaborado por Rodrigues et al. (2012), vejamos como se apresentam as referências às pessoas do discurso, conforme os momentos da carta-testamento de Getúlio (entre parênteses, a quantidade de ocorrências):

\begin{tabular}{|c|c|}
\hline Plano de texto & Pessoas do discurso \\
\hline Abertura & $\begin{array}{l}\text { 1a p. sg: "mim" (1), "me" (3), “minha" (2), “eu" (2) }{ }^{1} \\
\text { 2a p. pl: "o povo e principalmente os humildes" (1) } \\
\text { 1a p. pl: --- } \\
\text { 3a p. pl: "as forças" (1), sujeito indeterminado (6) }\end{array}$ \\
\hline $\begin{array}{l}\text { Defesa pessoal e do } \\
\text { governo }\end{array}$ & $\begin{array}{l}\text { 1a p. sg: "mim" (1), "me" (2), "meu" (1), "eu" (11) } \\
\text { 2a p. pl: "o povo" (3), "o trabalhador" (1), "vos" (1) } \\
\text { 1a p. pl: "nosso/a/s" (3), "nós" (2) } \\
\text { 3a p. pl: "grupos econômicos e financeiros internacionais" (1), } \\
\text { "grupos internacionais" (1), "grupos nacionais revoltados con- } \\
\text { tra o regimem de garantia de trabalho" (1), sujeito indetermi- } \\
\text { nado (2), passiva sem agente (2) }\end{array}$ \\
\hline $\begin{array}{l}\text { Explicação causal } \\
\text { do suicídio }\end{array}$ & $\begin{array}{l}\text { 1a p. sg: "eu" (1), "minha" (1) } \\
\text { 2a p. pl: "o povo brasileiro" (1) } \\
\text { 1a p. pl: ---- } \\
\text { 3a p. pl: "as aves de rapina" (1) }\end{array}$ \\
\hline $\begin{array}{l}\text { Promessa e apelo à } \\
\text { resistência popular }\end{array}$ & $\begin{array}{l}\text { 1a p. sg: "eu" (1), "meu" (3) } \\
\text { 2a p. pl: "convosco" (1), "vos" (5), "vosso" (5) } \\
\text { 1a p. pl: "nos" (1) } \\
\text { 3a p. pl: ---- }\end{array}$ \\
\hline Vontade e legado & $\begin{array}{l}\text { 1a p. sg: "meu" (1), "me" (1), "minha" (1) } \\
\text { 2a p. pl: "vossa" (1) } \\
\text { 1a p. pl: ---- } \\
\text { 3a p. pl: "os que pensaram que me derrotaram" (1) }\end{array}$ \\
\hline $\begin{array}{l}\text { Avaliação da escol- } \\
\text { ha pelo suicídio }\end{array}$ & $\begin{array}{l}\text { 1a p. sg: "me" (1), “eu" (1), “meu" (2) } \\
\text { 2a p. pl: "o povo" (1), "esse povo" (1), "seu/sua" (2) } \\
\text { 1a p. pl: ---- } \\
\text { 3a p. pl: ---- }\end{array}$ \\
\hline $\begin{array}{l}\text { Síntese de sua } \\
\text { história }\end{array}$ & $\begin{array}{l}\text { 1a p. sg: "eu" (5), "meu" (1), "minha" (2) } \\
\text { 2a p. pl: "o povo" (1), "vos" (1) } \\
\text { 1a p. pl: ---- } \\
\text { 3a p. pl: ---- }\end{array}$ \\
\hline Fechamento & $\begin{array}{l}\text { 1a p. sg: “eu” (3) } \\
\text { 2a p. pl: ---- } \\
\text { 1a p. pl: ---- } \\
\text { 3a p. pl: ---- }\end{array}$ \\
\hline
\end{tabular}

Se fizermos uma análise puramente quantitativa, veremos que há 47 ocorrências de uso de 1a. p.sg., metade das quais aparecendo nos dois primeiros momentos da carta 
(Abertura, Defesa pessoal e do governo); 6 casos de 1a. p.pl., quase todos no segundo momento da carta; 24 exemplos de uso de 2a. p.pl., que estamos marcando aqui como usos prototípicos de vós/vosso, mas também como uso de povo como destinatário e não como 3a pessoa - metade desses casos aparece no momento de Promessa e apelo à resistência popular; 16 ocorrências de 3a. p.pl., marcando os inimigos, as "aves de rapina" - quase todos esses casos ocorrem nos dois primeiros momentos da carta.

Já numa análise mais qualitativa, não podemos desprezar o fato de que a construção do EU, do NÓS e dos OUTROS está enfatizada, na carta testamento, exatamente nos dois momentos iniciais do texto, quando parece que são colocadas as cartas na mesa para mostrar quem joga com quem. $\mathrm{O}$ EU se constrói não como oposição à $2 \mathrm{a}$ pessoa, como se poderia esperar, mas em oposição aos OUTROS, inimigos, à espreita para tomar o poder e maltratar o POVO/VÓS, que precisa ser protegido. Essa estratégia presente na carta é bastante semelhante ao que Maalej (2013) encontrou nos discursos de despedida de Mubarak: há sempre um EU que tudo sabe e tudo vê, salvador da pátria, que protege o POVO/VÓS dos OUTROS, os vorazes carrascos.

Essa construção textual-discursiva dos interlocutores que percebemos na carta-testamento também foi percebida por outros autores. Hanks (2008) defende que a dêixis desempenha um papel pragmático na interação social no discurso - posição também defendida por Maalej (2013, p. 640):

Para Hanks (2005, p.197), não há uso egocêntrico da dêixis, pois isso contradiz a centralidade interacional do discurso. Por isso, "no campo dêitico estamos lidando com a ocupação efetiva das posições" (Hanks 2005, p. 210-211), segundo a qual "referência dêitica é um compromisso social emergente na prática". Hanks (1992, p.53) argumenta que "dado que atos de referência são realizados interativamente, uma abordagem sociocêntrica é certa que será mais produtiva do que uma egocêntrica, mesmo quando o orador é o ponto de partida de referência"

Já para Pardillos (1995, p. 60), que analisa dêixis como estratégia persuasiva em anúncios publicitários - textos fortemente marcados por aspectos culturais -, os mecanismos dêiticos envolvem os papéis desempenhados pelos interlocutores. Para o autor, os anúncios despertam nosso lado egoísta, ao contrário de textos políticos, que apontam para o "bem comum" - como os analisados neste artigo e por Maalej (2013). A conclusão de Pardillos a respeito do uso de NÓS em anúncios é semelhante à que estamos chegando, em conjunto com Maalej: indicando EU+alguém, NÓS marca a inclusão ou não de VOCÊ no discurso, o que pode carregar um valor persuasivo. Isso porque, para Pardillos (1995, p. 66), "os termos dêiticos criam um contexto suposto no qual os participantes no discurso persuasivo podem, mesmo à distância, sentir como se estivessem se enfrentando" .

Assim, na carta testamento, os dêiticos de pessoa também parecem demonstrar muito mais que os integrantes do jogo discursivo, pois denotam jogos de força, marcando a dis-

7 Tradução nossa: "For Hanks (2005: 197), there is no egocentric use of deixis since this contradicts the interaction-centricity of speech. For that, "in the deictic field we are dealing with the actual occupancy of the positions" (Hanks 2005: 210-11), whereby "deictic reference is a social engagement emergent in practice". Hanks (1992: 53) argues that "given that acts of reference are interactively accomplished, a sociocentric approach is certain to be more productive than an egocentric one, even when the speaker is the primary ground of reference"" (cf. MAALEJ, 2013, p. 640).

8 Tradução nossa: "deictic terms create an, as it were, alleged context where participants in persuasive discourse can, even at a distance, feel as if they were facing each other" (cf. PARDILLOS, 1995, p. 66). 
puta pelo poder. Desempenham, portanto, papel persuasivo, marcando o posicionamento do escriba diante dos demais interlocutores, incluindo-os ou não no discurso e colocandose como EU-salvador e mártir da pátria.

\section{Anáforas Indiretas na carta testamento}

A rigor, os objetos de discurso introduzidos no texto são passíveis de serem retomados por uma estratégia anafórica retrospectiva ou prospectiva (caso da catáfora): havendo correferencialidade, trata-se de anáfora direta $(\mathrm{AD})$; não havendo, temos a anáfora indireta (AI). Segundo Conte (2003), há ainda um terceiro tipo, o encapsulamento, que estaria num meio-termo entre os dois tipos clássicos de anáfora, pois não é totalmente correferencial como a $\mathrm{AD}$, mas sumariza uma parte do texto e a ela se refere, necessitando de um certo grau de inferência para ser compreendida. Há também a dêixis, estratégia referencial comumente associada ao entorno sociocomunicacional, conforme expusemos e exploramos na sessão anterior deste artigo. Finalmente, vale lembrar, com Cavalcante (2011, p.122), que o objeto de discurso nem sempre se explicita por uma expressão referencial. Isso quer dizer que não apenas as formas referenciais permitem a construção de objetos de discurso.

Conforme observa Kleiber (2001), as AI (que o autor chama de Anáforas Associativas), constituem um dos mais importantes mecanismos de coerência dada a sua alta incidência. Com efeito, elas desempenham um papel fundamental na construção dos sentidos do texto e na orientação argumentativa. O autor destaca ainda que o fato de as AI permitirem que se conheça o novo sobre as bases de algo já conhecido faz delas um procedimento de coerência textual especialmente econômico e original. Um dos problemas levantados por Kleiber encontra-se no reconhecimento do referente adequado ao qual a anáfora remeta, dificuldade que se justifica pelo fato de não haver correferência, exigindo um trabalho inferencial do leitor, o que demanda um maior esforço cognitivo por parte deste.

Adotamos no presente texto a definição de Marcuschi (2005, p. 59) para Anáfora Indireta:

No caso da Anáfora Indireta, trata-se de expressões definidas [e expressões indefinidas e pronominais] que se acham na dependência interpretativa em relação a determinadas expressões [ou informações constantes] da estrutura textual precedente [ou subsequente] e que têm duas funções referenciais textuais: a introdução de novos referentes (até aí não nomeados explicitamente) e a continuação da relação referencial global.

A definição proposta por Marcuschi nos permite extrair, na esteira de Kleiber, que a AI tem seu referente identificado devido a informações presentes no contexto textual, mas que ela não é correferencial, ou seja, não há identidade entre ela e o referente ao qual ela remete. Trata-se de apresentar objetos que não foram mencionados no contexto, tomando-os como conhecidos. Há entre as duas entidades, o referente e a AI, uma relação discursiva-cognitiva (KLEIBER, 2001) que está na base da construção das inferências necessárias para o reconhecimento da anáfora e do referente ao qual ela se liga. $\mathrm{O}$ fato é que nem sempre o referente se encontra presente no cotexto, podendo ser ativado por elementos dele que permitem estabelecer ligações, em nossa memória, necessárias à construção de relações de sentido pertinentes ou mesmo dependendo do contexto, no qual se encontra implícito.

A observação dos principais referentes introduzidos no início da carta testamento nos permite identificar uma dinâmica referencial que instaura uma relação entre três objetos de discurso a serem construídos no desenvolvimento da textualidade: os interesses contra o povo, eu e o povo. 
Com respeito ao referente "os interesses contra o povo" ao longo do texto, por meio de várias remissões, o enunciador consolidará uma oposição relativamente a "eu". Assim, observamos a AI "grupos econômicos e financeiros internacionais", ancorada no conhecimento da posição nacionalista declaradamente assumida por Getúlio. Mais adiante, "grupos internacionais" e "grupos nacionais revoltados contra o regime de garantia do trabalho" remetem novamente a "os interesses contra o povo"; essas AI se dão por um processo meronímico (Marcuschi, 2005): os grupos mencionados se incluem, são parte dos interesses contra o povo, presente no cotexto. Além disso, vale destacar que "garantia do trabalho" remetem a "eu", inferência possível a partir da informação anteriormente exposta no texto de que "eu" "instaurei um regime de liberdade social". Mais adiante, "os ódios" constitui outra AI para "os interesses contra o novo". "Os interesses contra o novo" é rotulado em um terceiro momento da carta como "aves de rapina", reforçada pela anáfora indireta "a fome", que, por uma relação de causa e efeito, remete a "os interesses contra o povo"; eles serão os causadores da fome do povo.

As informações precedentes a respeito de "os interesses contra o povo" permitem associar a anáfora indireta "a fome" a esse referente, por uma relação de causa/consequência; também "o ódio" remete ao referente "os interesses contra o povo", que vem sendo ressignificado ao longo do texto; considerando ainda o processo de construção do objeto de discurso ao longo do texto, é possível associar "a espoliação do Brasil” e "a espoliação do povo" a "os interesses contra o novo".

O referente "a lei de lucros extraordinários" constitui também uma anáfora indireta relativamente a "eu" e exige do leitor que tenha conhecimento de que a referida lei foi proposta por "eu". Considerando o contexto da carta e seu destinatário, podemos inferir que o reconhecimento dessa anáfora indireta ancorada no modelo do mundo textual (Marcuschi, 2005) não constitui dificuldade nem mesmo para o leitor atual, uma vez que o texto, nesse ponto, está apresentando uma enumeração de atos tomados contra "eu", o que permite inferir a origem da proposta da lei. O mesmo acontece com a afirmação de que "a Eletrobras foi obstaculada até o desespero", que, embora contando com conhecimento do destinatário da época, nos permite, no presente, inferir, por meio de uma leitura atenta, que foi "eu" quem criou a Eletrobras, e o que a "obstaculou" foram "os interesses contra o povo".

Com efeito, tudo o que se opõe ao povo e a "eu" remete a "os interesses contra o povo". Assim pautado na estratégia de oposição, o enunciador constrói também o objeto de discurso "eu", diferenciando-se e distanciando-se de "ele", ou seja, "os interesses contra o povo". Esse objeto de discurso se constitui de grupos nacionais e internacionais cujos interesses vão de encontro aos ideais de "eu", comprometido com "o povo".

Embora o referente "o povo" seja retomado várias vezes por anáforas diretas, tanto por repetição do mesmo item lexical, quanto por expansão em um grupo nominal contendo o mesmo item lexical (o povo brasileiro), podemos destacar várias anáforas indiretas que também remetem a "o povo". Por um processo inferencial que nos permite associar povo à camada mais humilde da sociedade, "os humildes" retoma "o povo" e, mais adiante, "o trabalhador" faz o mesmo. O indefinido em "se as aves de rapina querem o sangue de alguém" também permite remeter "alguém" a "povo", tratando-se de uma AI ancorada no modelo do mundo textual, ou seja, em informações explicitadas precedentemente no texto (MARCUSCHI, 2005, p.64). Somente "o povo" cabe como alvo das aves de rapina no texto. E em seu lugar, o enunciador oferece-se em sacrifício.

Vale observar a mudança de enunciação no terceiro e quarto parágrafos, quando "eu" explicita que seu destinatário é "o povo", a quem passa a chamar de "vos": "estar sempre 
convosco", "vos humilharem", "vossa porta", vosso peito", "vos e vossos filhos", "vos vilipendiarem", "vossa bandeira", "vossa consciência”. Aqui, como já lembramos, observamos a dêixis de pessoa referindo-se não apenas às pessoas do discurso, mas marcandolhes o lugar na arquitetura argumentativa do texto, uma vez que este é o momento em que o povo surge como destinatário. Porém, no fim do texto, retorna a designação "o povo", voltando à terceira pessoa para designá-lo: "povo escravo", "sua alma", "seu resgate".

No último parágrafo da carta, vários grupos nominais remetem, por um lado, ora a "povo" ora a "eu" e, por outro, a "os interesses contra o povo", reforçando a ligação entre "eu" e "povo". Assim é que encontramos "a espoliação do Brasil" e, logo em seguida, "a espoliação do povo", o que permite estabelecer, pela repetição do item nominal que refere uma ação reiterada, uma relação de identidade entre "Brasil" e "povo", possível pelo caráter inclusivo: Brasil inclui povo brasileiro, espoliação do Brasil é, portanto, também espoliação do povo brasileiro. No mesmo último parágrafo, ancorados no contexto, os grupos nominais "o ódio", "a infâmia", "a calúnia" que não abateram o ânimo de "eu" remetem a "os interesses contra o povo" e reforçam a relação de oposição entre "eu" e "os interesses contra o povo". Além disso, mantem-se a oscilação na enunciação para referir "povo", que aparece, no início do parágrafo em terceira pessoa e passa, no fim, a "vos", reinstaurando a relação intersubjetiva da carta. Vale ressaltar que, encontrando-se nas últimas linhas da carta, essa mudança na enunciação tem a força de eternizar o povo como interlocutor direto da missiva, assim como dá por certa a comunhão de interesses entre "o povo" e "eu”, em oposição a "os interesses contra o povo". "Eu" se eterniza como aquele que, ao enunciar "ofereço minha morte", pretende salvar o povo de "os interesses contra o povo". "Eu" procura eternizar-se assim como o grande herói, mártir destemido ("nada receio"), na certeza de que a história o reconhecerá como tal ("saio da vida para entrar na história").

Considerando, no entanto, que, como destaca Ducrot, (1984), "eu" não pode elogiarse, pois seria pretencioso afirmar avaliações positivas sobre sua própria pessoa, o que poderia irritar o auditório, a estratégia é remeter a "eu" por vias indiretas. Encontramos, nos três últimos parágrafos, uma série de anáforas indiretas que remetem, por diversos tipos de relações, a "eu". Assim temos relações meronímicas (MARCUSCHI, 2005, p. 62) com "meu sangue", "minha vida", "cada gota do meu sangue"; e, por meio de "meu sacrifício", "minha vitória", "minha morte", o enunciador nomeia os processos que com ele ocorrem (id., p.66). Essas remissões permitem que "eu” se apresente como o mártir vitorioso (aos que me derrotaram respondo com minha vitória). Trata-se de uma estratégia que consiste em de alguma forma "envolver a enunciação" ("envelopper", segundo Maingueneau, 1998) sem que os atributos pretendidos estejam explícitos no enunciado, mas por meio da escolha de palavras que mostrem por si as qualidades de "eu".

\section{Os verbos na construção de objetos de discurso argumentativamente orientados}

Os estudos dos processos de referenciação centram-se especialmente na questão dos nomes, das sequências nominais e dos pronomes, cuja função é designar os referentes, trazendo-os à tona na linearidade textual, retomá-los, remeter a eles, ampliando os seus sentidos de acordo com um querer dizer, construindo, enfim, objetos de discurso.

Concordamos com Marcuschi (2006, p.13) que "a realidade não é um dado a priori, mas uma construção discursiva motivada”. O processo de referenciação cumpre, sem dúvida, um papel fundamental na construção dessa realidade discursiva, mas a construção da realidade discursiva não se atém aos processos de referenciação. Além disso, o 
processo de referenciação, conforme expusemos já neste trabalho, não se limita ao ato de designar, embora funde-se nele; tal como o compreendemos atualmente, trata-se de um processo bem mais amplo que consiste na construção de objetos de discurso (MONDADA E DUBOIS, 2003). Além disso, conforme já expusemos neste artigo, os objetos de discurso não necessariamente estão presentes no contexto, nem precisam estar explicitados por expressões referenciais (CAVALCANTE, 2011). Desse ponto de vista, é importante considerar outros fenômenos que, aliando-se aos processos referenciais, auxiliam a construção dos sentidos, orientam argumentativamente, corroboram a construção dos objetos de discurso.

Concordamos com Milner (2003) que o estatuto referencial dos nomes e dos verbos não é igual, entretanto não podemos negligenciar os verbos como manifestações das ações dos objetos de discurso; encaramos, assim, os verbos como elementos cujos sentidos se agregam aos referentes ampliando os seus sentidos, o que confere aos verbos um lugar na construção dos objetos de discurso. Esse papel se torna ainda mais evidente quando o referente é "eu”, uma vez que "eu” não pode, conforme destacamos anteriormente neste texto, "elogiar-se a si mesmo". Sendo assim, a construção do objeto de discurso "eu", além do recurso às anáforas indiretas e dos dêiticos de pessoa, lança mão de um processo de implicação a partir das ações de "eu" no desenvolvimento do texto. Por conseguinte, ocupam lugar de destaque, na construção de uma imagem de "eu", a escolha dos verbos, especialmente os verbos de ação, denotando os atos realizados por "eu", mas não apenas por “eu”. Compreendemos, com Kerbrat-Orecchioni (1980, 1997), que o verbo constitui uma das principais ferramentas para evidenciar uma atitude frente aos fatos enunciados e marcar intenções frente aos interlocutores. Eles permitem exprimir tanto opinião, como julgamento e sentimento, marcando uma intenção de dizer.

Na carta-testamento de Getúlio Vargas, a escolha dos verbos evidencia uma intenção de mostrar "eu" como fazedor em favor do povo: ao afirmar que "sempre defendi o povo e principalmente os humildes", "eu" se atribui a qualidade de "defensor" do povo. Foi também por sua ação que "eu" se tornou "chefe de uma revolução", que é um "vencedor", o "libertador da sociedade" ("iniciei um trabalho de libertação e instaurei um regime de liberdade social"); mais do que simples libertador da sociedade, é um libertador da nação ("quis crear a liberdade nacional"). Por fim, "eu" se apresenta como lutador incansável ("tenho lutado, resistindo a uma agressão constante, tudo suportado em silêncio"), mártir pelo povo ("ofereço em holocausto a minha vida", "ofereço a minha morte"). Podemos assim afirmar que as ações ligadas a eu pressupõem atributos de "eu”, esses atributos permitem construir o objeto de discurso "eu" dotado de qualidades positivas: vencedor, libertador, lutador.

A leitura da carta nos permite também observar, na relação intersubjetiva, relativamente a "eu", dois referentes dos quais "eu" se diferencia: "eles", introduzido pelo referente "os interesses contra o novo", e "vós", representado pelo referente "o povo", destinatário da carta-testamento. Assim, ainda relativamente ao emprego de verbos na construção do objeto de discurso "eu", vale destacar a escolha dos verbos que expressam as ações de "eles" e das quais "eu" constitui o alvo direto ("não me acusam, me insultam; não me combatem, caluniam"); ou indireto, por meio de um referente que remeta a "eu", por se tratar seja de algo que faz parte de "eu" ("precisam sufocar a minha voz"), seja de algum fato ou processo relativo a "eu" ("não me dão direito de defesa; impedir a minha ação; não abateram meu ânimo"). É importante ressaltar que os verbos para expressar as atitudes de "eles" em relação a "eu" trazem todos um caráter avaliativo negativo, por 


\section{Conexão Letras}

designarem ações negativas (insultar, caluniar), ou impeditivas da ação de "eu”("sufocar a voz", "não dão direito de defesa", "impedir","abater o ânimo"), escolha que reforça a construção do objeto de discurso "eu" como mártir e herói.

Dentre as construções verbais por meio das quais o locutor pode manifestar uma atitude frente ao enunciado, cabe ainda destacar a passiva, noção fundamentalmente pragmática (GIVÓN,1984, 1990) e portadora de sentidos. Com efeito, o mesmo evento semanticamente transitivo, codificado pelo mesmo verbo, mesmo agente e paciente pode ser tratado sob diferentes pontos de vista pragmático-discursivos. Essas perspectivas envolvem sobretudo, embora não exclusivamente, a relativa topicalidade do agente e do paciente; o emprego da passiva topicaliza o não agente. Na passiva, o agente de um evento semanticamente transitivo é demovido de sua posição de tópico, ou até mesmo suprimido, supressão que pode ocorrer por razões pessoais, inter-pessoais, sociais ou culturais.

Várias razões podem conduzir à escolha de uma construção na passiva em detrimento de uma na ativa (DIK, 1997). O enunciador pode, por exemplo, se identificar mais com objeto na ativa do que com o sujeito na ativa, colocando-se na posição de paciente, o que também explicita uma isenção de responsabilidade perante a ação expressa pelo verbo, ou seja, ele é obrigado a submeter-se a ela, como em "sigo o destino que me é imposto", em que "eu" se mostra sem opção para não seguir.

A apassivação, corrigindo uma construção ativa inicial em primeira pessoa, se inclui nas escolhas que provocam um descomprometimento do enunciador, que, segundo Neves (1996), se retira da posição de sujeito, facilitando o seu distanciamento do enunciado. Reforçando este postulado, Coracini (1991) assevera que as formas passivas que não explicitam o verdadeiro agente do processo descomprometem o locutor com relação à ação. O uso da voz passiva, conforme lembra Abreu (1990) é também um procedimento de impessoalização adequado aos textos escritos. Tratando-se de verbos de ação cuja representação semântica requer um agente, somos levados a interpretar que houve uma intenção da parte do enunciador em omitir o agente, que, conforme a proposta de Perini (1996, p.271), seria representado por "uma entidade animada não identificada”. É o que acontece, por exemplo no excerto: "A lei de lucros extraordinários foi detida no Congresso". A passiva sem explicitação do agente deixa para o leitor a tarefa de inferir quem representaria o agente, sugerindo, a partir do contexto textual, que a responsabilidade pela ação expressa pelo verbo é de "as forças contra o povo".

\section{Considerações finais}

Destacamos, na análise da carta testamento de Getúlio Vargas, não apenas os grupos nominais como fenômeno fundamental no processo de construção referencial de objetos de discursos, mas também a presença dos dêiticos e seu papel argumentativo, quando o referente é "eu", marcando uma tomada de posição do enunciador ao colocar-se frente a possíveis interlocutores e opositores, assumindo uma posição; observamos ainda a participação dos verbos denotando ações de "eu", revelando ações que contribuem para o processo de construção referencial respaldado na coerência entre as ações de "eu" e o objeto de discurso "eu" posto no texto.

Assim, podemos afirmar que a análise apresentada corrobora a afirmação de Cavalcante (2011), à qual já fizemos referência neste artigo, de que o objeto de discurso pode ser construído também por meio de outros recursos linguísticos e não apenas por formas referenciais. Além disso, vale observar que verbos e mecanismos dêiticos de pessoa cons- 
tituem marcas de subjetividade, podendo apresentar caráter persuasivo, e, nesse sentido, concorrem para a força argumentativa dos processos de referenciação, evidenciando a importância desse fenômeno para a defesa de um ponto de vista.

\section{Referências}

ABREU, A. S. Curso de redação. São Paulo: Ática, 1990.

APOTHÉLOZ, D.; PEKAREK DOEHLER, S. Nouvelles perspectives sur la référence: des approches informationnelles aux Approches Interactionnelles. Verbum, XXV, 2003, 2. p. 109-136.

BENVENISTE, É. Problèmes de linguistique générale,1. Paris: Gallimard, 1997[1966]. . Problèmes de linguistique générale,2. Paris: Gallimard, 1997[1974].

BUHLER, K. The deictic field of language and deictic words. In: JARVELLA, R.J.; KLEIN, W. (eds.) Speech, place and action: studies in deixis and related topics. New York: John Wiley and Sons, 1982. p. 9-30.

CAVALCANTE, M. Referenciação: sobre coisas ditas e não ditas. Fortaleza: EdUFC, 2011.

. et al. (org.). Referenciação. São Paulo: Contexto, 2003.

; SANTOS, L. W. dos. Referenciação e marcas de conhecimento partilhado.

Linguagem em (Dis)curso, v. 12, n. 3, set./dez. 2012, p. 657-681.

; CUSTÓDIO FO.; BRITO, Referenciação: conceitos e aplicações. São Paulo:

Cortez, 2013.

CIULLA, A. (org.) Referenciação Clássicos da Linguística 1. São Paulo: Contexto, 2003. p.177-190.

CONTE, M-E. Encapsulamento anafórico. In: CAVALCANTE, M. M.; RODRIGUES, B. B.;

CORACINI, M. J. Um fazer persuasivo. São Paulo: EDUC; Campinas: Pontes, 1991. CORNISH, F. Degrees of Indirectness: Two Types of Implicit Referents and their Retrieval via Unaccented Pronouns. In: BRANCO, António; McEnery, Tony; MITKOV, Ruslan (ed.). Linguistic, cognitive and computational modelling. Amsterdam: John Benjamins Publishing Company, 2005. p. 199-220.

. Deictic, discourse deictic and anaphoric uses of demonstrative expressions

in English. Workshop "Anaphoric uses of demonstrative expressions", System und Variation, 29th DGfS Annual Meeting, Universität Siegen, Germany (28th February-2nd March 2007). [mimeo]

DIK, S. The theory of functional grammar part 1. Berlin/NewYork: Mouton de Gruyter, 1997.

DUCROT, O. Dire et ne pas dire. Paris: Hermann, 1972.

. Le Dire et le Dit. Paris: Minuit, 1984.

EHLICH, K., Anaphora and deixis: same, similar or different? In: JARVELLA, R.J.; KLEIN, W. (ed.). Speech, place and action: studies in deixis and related topics. New York; John Wiley and Sons, 1982. p. 315-338.

FONSECA, Fernanda Irene. Deixis, Tempo e Narração. Porto: Fundação Eng. António de Almeida, 1992.

GIVÓN, T. Syntax-a functional-typological introduction. v. 2. Amsterdam/Philadelphia: John Benjamins Publishing Company, 1984,1990. 
HANKS, W. Incursões no campo dêitico. In: . Língua como prática social. São

Paulo: Cortez, 2008. p. 204-227.

KERBRAT-ORECCHIONI, C. L'énonciation. Paris: Armand Colin, 1997[1980].

KLEIBER, G. L'anaphore associative. Paris: PUF, 2001.

KOCH, I. Desvendando os segredos do texto. São Paulo: Cortez, 2003.

. As tramas do texto. São Paulo: Contexto, 2015.

. Referenciação e orientação argumentativa. In: KOCH, I. V.; MORATO, E. M.;

BENTES, A. C. (org.) Referenciação de Discurso. São Paulo: Contexto, 2005. p. 33-52. ; ELIAS, V. Ler e compreender: os sentidos do texto, São Paulo: Contexto, 2006.

2009. . Ler e Escrever: estratégias de produção textual. São Paulo: Contexto,

LEVINSON, S. Pragmatics. Cambridge: Cambridge University Press, 1983.

LYONS, J.. Semantics. Cambridge; Cambridge University Press. 2v, 1977.

MAALEJ, Z.A. Framing and manipulation of person deixis in Hosni Mubarak's last three speeches: a cognitive-pragmatic approach. Pragmatics, 23:4, 2013. p. 633-659.

MAINGUENEAU, D. Analyser les textes de communication. Paris: Dunod, 1998.

MARCUSCHI, L. A. Anáfora Indireta: o barco textual e suas âncoras. In: KOCH, I.

V.; MORATO, E. M.; BENTES, A. C. (org.). Referenciação de Discurso. São Paulo:

Contexto, 2005. p.53-101.

2008.

. Produção textual, análise de gêneros e compreensão. 3. ed. São Paulo: Parábola,

Referenciação e Progressão Tópica: aspectos cognitivos e textuais. Caderno de

Estudos Linguísticos, Campinas, 48 (1), 2006, p. 7-22.

MARMARIDOU, S. Pragmatic Meaning and Cognition. Amsterdam/Philadelphia:

John Benjamins Publishing Company, 2000. p. 62-103.

MILNER, J-C. Reflexões sobre a referência e a correferência. In: CAVALCANTE, M.

M.; RODRIGUES, B. B.; CIULLA, A. (org.). Referenciação. São Paulo: Contexto, 2003. p. 85-130.

MONDADA, L. A referência como trabalho interativo: a construção da visibilidade do detalhe anatômico durante uma operação cirúrgica. In: KOCH, I. G. V.; MORATO, E. M.; BENTES, A. C. (Org.). Referenciação e discurso. São Paulo: Contexto, 2005. p.11-31.

MONDADA, L. \& Dubois, D. Construção dos objetos de discurso e categorização: uma abordagem dos processos de referenciação. In: CAVALCANTE, M. M.; RODRIGUES, B. B.; CIULLA, A. (org.). Referenciação. São Paulo: Contexto, 2003. p.17-52.

NEVES, M. H. de M. A Modalidade. In: KOCH, I. G. V. (org.). Gramática do

Português Falado. v. VI. Campinas: Edunicamp/ FAPESP, 1996. p. 163-199.

PARDILLOS, M. A. C. Deixis as a reference to an alleged shared situation in persuasive discourse. Revista Alicantina de Estudios Ingleses 8, 1995, p. 57-67.

PERINI, M. Gramática Descritiva do Português. São Paulo: Ática, 1996.

REICHLER-BEGUELIN, Marie-José. Anaphore, cataphore et mémoire discursive. In:

CHAROLLES, Michel (dir.). Pratiques, n. 57, Metz, 1988, p. 15-43.

RODRIGUES, M. G. S.; SILVA NETO, J.G.; PASSEGGI, L.; MARQUESI, S. C. A

Carta-Testamento de Getúlio Vargas (1882-1954): genericidade e organização textual no discurso político. Filologia Linguística Portuguesa., n. 14(2), p. 285-307, 2012.

SANTOS, L. W. dos; CAVALCANTE, M. Referenciação: continuum anáfora-dêixis.

Revista Intersecções, ed. 12, ano 7 , n.1, maio/2014, p. 224-246.

SCHIFFRIN, D. Between text and context: Deixis, anaphora, and the meaning of then.

Text 10 (3), 1990, p. 245-270. 